\title{
Residential area and physical activity: A multi-level study of 68,000 adults in Stockholm County
}

\author{
ANNA C. SVENSSON ${ }^{1}$, JOANNA STJERNSCHANTZ FORSBERG ${ }^{2,3}$, DOMINIKA \\ SEBLOVA $^{1,2} \&$ ANTON LAGER $^{1,2}$
}

${ }^{1}$ Department of Public Health Sciences, Karolinska Institutet, Sweden, ${ }^{2}$ Centre for Epidemiology and Community Medicine, Stockholm County Council, Sweden, and ${ }^{3}$ Department of Public Health and Caring Sciences, Uppsala University, Sweden

\begin{abstract}
Aim: To determine whether there are systematic differences in physical activity between residential areas after extensive control for sociodemographic factors at the individual level. Methods: Multi-level regressions of walking/bicycling, sedentary activities, household work and exercise were carried out in a representative sample of 68,303 adults in 39 residential areas in Stockholm County, first adjusting at the individual level for country of birth, sex, age, education, occupational class and income. The type of housing was then considered at the individual level or, for walking/ bicycling and exercise, at both the individual and area levels (as a measure of area density). Results: After adjustment for sociodemographic factors, differences between residential areas remained in walking/bicycling, corresponding to $0.27 \mathrm{SD}$, or $50 \mathrm{~min} /$ week between the most and least active areas. Forty per cent of this difference could be explained by the type of housing at the area level. For sedentary activities and household work, respectively, much of the variation that remained after adjustment for sociodemographic factors was, in turn, explained by the type of housing at the individual level, leaving a difference of $0.16 \mathrm{SD}(80 \mathrm{~min} / \mathrm{week})$ and $0.13 \mathrm{SD}$ (60 min/week), respectively. For exercise, the corresponding difference was $0.11 \mathrm{SD}$ (11 min/week, not sensitive to housing). Conclusions: Area level factors may influence walking/bicycling. High area density was associated with more activity. However, high density also comes with a type of housing (apartments) that is associated with less household work and, surprisingly, more sedentary activities, introducing a challenging trade-off. The differences in exercise were smaller than for all other types of activities.
\end{abstract}

Key Words: Housing, population density, socioeconomic factors, physical activity, physical inactivity, multi-level regression

\section{Introduction}

Physical activity has both long- and short-term health benefits and is a key risk factor for cardiovascular disease [1], certain forms of cancer [2] and type 2 diabetes [3]. It is estimated that one in three adults does not reach the WHO recommendations of at least $150 \mathrm{~min}$ of moderate intensity activity per week [4]. An estimated 2.2 million deaths and 42.1 million disability-adjusted life years (DALYs) lost representing about $1.8 \%$ of the global DALYs - are attributable to low physical activity each year (http:// vizhub.healthdata.org/gbd-compare/).
Physical activity can be promoted through behaviour-oriented and individualized programmes, but these are often very resource-intensive and typically have small to moderate effects that do not always last after the intervention has ended [5-7]. The promotion of physical activity through structural changes, such as planning of the physical environment, may be both more cost-effective and more equitable because it reaches large groups of the population and can be effective over long periods of time [8]. 
There are large differences in public health between different municipalities and urban districts in Stockholm County $[9,10]$. For example, a recent report showed that disadvantaged areas had a higher prevalence of obesity and unhealthy lifestyle habits [11]. To the extent that such area differences are contextual, i.e. more than a direct consequence of differences in population composition, they could possibly help us to understand how to plan for a health-promoting environment.

However, because individual sociodemographic factors, such as age, education and income level, are such powerful determinants of health and health behaviours, including levels of physical activity [12], much of these area differences are likely to be driven by differences in population composition. In 2013, the difference in mean yearly income between people in the most and least affluent regions of Stockholm County, Danderyd and Botkyrka, was 350,000 SEK (564,000 vs, 214,000 SEK) (http://www.scb.se).

The aim of this study was to determine whether there are systematic differences in physical activity between residential areas after extensive control for sociodemographic factors at the individual level. To this end, we used a multi-level approach to analyse differences in physical activity between residential areas in Stockholm County after controlling for age, income, education, occupational class and country of birth. Three domains of leisure time physical activity, available to us from the Stockholm County Council public health surveys, were analysed: home- and household work and gardening, walking and bicycling, and exercise. In addition, inactivity (sedentary leisure time, e.g. watching TV, sitting) was analysed. It was also investigated whether the type of housing, both at the individual and the area level, had an impact on the regional variation in physical activity.

\section{Methods}

The study was based on data from the Stockholm Public Health Cohort, a population-based cohort study that was established within the framework of the Stockholm County Council public health surveys. In 2010 , the survey was sent out to 55,341 randomly selected people from the adult population of Stockholm County. To avoid under-representation of smaller districts, a stratified study design was used. In total, 30,767 people responded, corresponding to a response rate of $55.6 \%$. A similar questionnaire was sent out to 55,587 people who had previously responded to one or more surveys, of which $44,003(77.4 \%)$ responded. In total, the cohort consisted of 74,770 people [13]. We used information from the 68,303 participants with full data on all included variables.
The questionnaire consisted of about 100 questions about health, lifestyle, family status, housing and living environment, physical and psychosocial work environment, and other factors. Self-reported data were supplemented with information from Swedish registers. The project was approved by the Stockholm Regional Ethical Review Board (Dnr 2010/1879_31/5; Dnr 2007/545_31).

\section{Sociodemographic background factors}

Information about occupational class was obtained from the questionnaire. Participants were asked to answer the following question: What is/was your job or work duties? If currently not working, the participants were asked to answer with reference to their latest job/work duties. Occupational class was classified according to the Swedish socioeconomic classification developed by Statistics Sweden [14]. Participants were grouped into six categories: unskilled workers, skilled workers, lower non-manual employees, intermediate non-manual employees, higher non-manual employees and self-employed.

Educational level was obtained by record linkage with the Longitudinal Integration Database for Health Insurance and Labour Market Studies (LISA), a register kept at Statistics Sweden that consists of family and individual data on socioeconomic parameters [15]. We grouped education in seven categories based on each participant's highest achieved educational level: not finished compulsory education; compulsory education; $<3$ years of upper secondary education; 3 years of upper secondary education; $<3$ years of university education; $\geqslant 3$ years of university education; and postgraduate education.

Information regarding household disposable income was also retrieved from the LISA register [15]. This variable is the individualized weighted average income, obtained by calculating the sum of all the family members' disposable incomes multiplied by the individual consumption weights, divided by their aggregate consumption weight. It includes all earnings and income from self-employment for both spouses, all cash benefits that the family receives and deductions to account for taxation. Disposable income was categorized into fifths according to quintiles.

Information on age and country of birth was retrieved from the Swedish Total Population Register. Age was categorized as 18-24, 25-34, 35-44, 45-54, $55-64,65-74$ and $\geqslant 75$ years. Country of birth was categorized into Sweden, other Nordic countries, other European countries, North America, South America, Asia, Africa, Oceania and other countries. 


\section{Type of housing}

Information on housing was based on the questionnaire in which participants were asked to answer the following question: In what type of housing do you live? As a measure of the density in each municipality, we used the proportion of respondents who stated that they were living in an 'own house or terraced house'.

\section{Physical activity}

Information about physical activity was assessed from Stockholm Health Survey 2010. There were five to seven predefined categories for time spent on different activities: home/household work and gardening (from $<1$ to $>5 \mathrm{~h} /$ day); walking/bicycling (from hardly ever to $>2 \mathrm{~h} /$ day); sitting, watching $\mathrm{TV}$, reading (from $<1 \mathrm{~h} /$ day to $>6 \mathrm{~h} /$ day); and exercise (not including bicycling and walking) (from hardly ever to $>5 \mathrm{~h} /$ week). The instrument for measuring physical activity was initially developed by Norman et al. [16] and has been validated and used in several studies [17-19]. As the question enables the calculation of a metabolic equivalent of task, results can be compared with those from other studies on physical activity.

\section{Statistical analyses}

Linear multi-level regression was used to quantify the area differences for the different domains of physical activity. Models were fitted using the PROC MIXED procedure in SAS software v9.3. For each domain of physical activity, we fitted an empty model where the geographical areas were modelled as random intercepts (model 1). In the subsequent models, individual level sociodemographic factors were added as fixed effects (age, education, occupational class, income, country of birth) (model 2), allowing for indirect inference regarding area level effects. For walking/ bicycling and exercise a model was created that, in addition to including all level 1 fixed effects, also adjusted for the area variable 'proportion living in own house or terraced house' as well as the individual's own housing (model 3). The covariate measuring the proportion living in an own house or terraced house was chosen as a measure of area density, as previous research has demonstrated a correlation between density and walking, bicycling and recreational physical activity $[20,21]$. This variable was also known on the individual level for all participants. Model 3 analysing 'home- and household work and gardening' and 'sitting/watching TV/reading' were only adjusted for individual housing because there was less reason to believe that such activities would be affected by housing at the area level.

All individual level covariates were analysed as categorical variables. All analyses were based on the same analytical sample $(n=68,303)$ where individuals who did not answer all the questions in the physical activity instrument, the questions on occupation or housing, or where data was missing on geographical area or income, were excluded from the analyses.

Effect sizes were expressed as standardized mean differences, relating the mean difference between the least and most active area to the (pooled) standard deviation in the (single-level) analysis, producing the average time spent on different activities in our sample (i.e. the first statistics presented in each of the following sections).

\section{Results}

The study sample characteristics with regard to the variables included in the analysis are summarized in Table I.

\section{Walking and bicycling}

On average, residents in Stockholm County spent 4 $\mathrm{h} /$ week (240 $\mathrm{min}$ ) bicycling or walking (SD $186 \mathrm{~min}$ ). The difference between the district where residents biked and walked the most and the district where they biked and walked the least was almost $1 \mathrm{~h} /$ week (54 min) (areas Östermalm and Skärholmen; Figure 1). When sociodemographic factors at the individual level were taken into account, notable area differences in bicycling and walking persisted. The difference between the most and least active districts decreased only marginally (to $50 \mathrm{~min} / \mathrm{week}$, a decrease of $6 \%$ ) after adjustments.

When adjusted for type of housing (among individuals and on the area level), the regional variation in walking and bicycling was substantially reduced. The difference between districts where people were the most and the least active decreased from just over $50 \mathrm{~min} /$ week to $30 \mathrm{~min}$, a reduction of $40 \%$.

\section{Exercise}

In addition to bicycling or walking, residents in Stockholm County on average spent $1 \mathrm{~h} 38 \mathrm{~min} /$ week exercising in their leisure time (SD $1 \mathrm{~h}$ $36 \mathrm{~min}$ ). The difference between the district where residents exercised the most and the one where they exercised the least was $20 \mathrm{~min} / \mathrm{week}$ (areas Östermalm and Rinkeby-Kista; Figure 2). After adjusting for sociodemographic factors, the maximum between-area difference decreased to 11 
Table I. Descriptive statistics.

\begin{tabular}{|c|c|c|c|c|c|c|}
\hline & Frequency & $\%$ & $\begin{array}{l}\text { Minimum } \\
\text { frequency } \\
\text { per area }\end{array}$ & $\begin{array}{l}\text { Maximum } \\
\text { frequency } \\
\text { per area }\end{array}$ & $\begin{array}{l}\text { Minimum } \\
\% \text { per area }\end{array}$ & $\begin{array}{l}\text { Maximum } \\
\% \text { per area }\end{array}$ \\
\hline \multicolumn{7}{|l|}{ Mode categories for physical activity } \\
\hline Bicycling or walking: $20-40 \mathrm{~min} /$ day & 27,765 & 40.7 & 375 & 1195 & 33.7 & 43.7 \\
\hline Exercise: $60-120 \mathrm{~min} /$ week & 17,903 & 26.2 & 233 & 719 & 20.4 & 26.3 \\
\hline Household work and gardening: $60-120 \mathrm{~min} /$ day & 29,296 & 42.9 & 396 & 1155 & 34.6 & 47.4 \\
\hline Sedentary leisure activities: $60-120 \mathrm{~min} /$ day & 25,617 & 37.5 & 316 & 1092 & 28.4 & 40.9 \\
\hline \multicolumn{7}{|c|}{ Individual sociodemographic and background factors } \\
\hline \multicolumn{7}{|l|}{ Sex } \\
\hline Men & 30,208 & 44.2 & 528 & 1180 & 40 & 47 \\
\hline Women & 38,095 & 55.8 & 662 & 1555 & 53 & 60 \\
\hline \multicolumn{7}{|l|}{ Age (years) } \\
\hline $18-24$ & 3001 & 4.4 & 48 & 127 & 2.3 & 7.6 \\
\hline $25-34$ & 7248 & 10.6 & 86 & 424 & 5.6 & 22.7 \\
\hline $35-44$ & 12,544 & 18.4 & 154 & 508 & 12.6 & 22.0 \\
\hline $45-54$ & 12,865 & 18.8 & 199 & 525 & 14.4 & 22.4 \\
\hline $55-64$ & 13,343 & 19.5 & 198 & 578 & 15.4 & 24.7 \\
\hline $65-74$ & 12,124 & 17.8 & 141 & 545 & 10.0 & 25.0 \\
\hline $75+$ & 7178 & 10.5 & 78 & 329 & 9.7 & 13.9 \\
\hline \multicolumn{7}{|l|}{ Country of birth } \\
\hline Sweden & 57,373 & 84.0 & 547 & 2432 & 47.9 & 91.9 \\
\hline Other Nordic & 3410 & 5.2 & 38 & 243 & 2.4 & 10.1 \\
\hline Other European & 3527 & 5.0 & 31 & 220 & 2.1 & 14.5 \\
\hline Asia & 2355 & 3.5 & 14 & 214 & 0.8 & 18.7 \\
\hline South America & 660 & 1.0 & 3 & 38 & 0.2 & 3.1 \\
\hline Africa & 617 & 0.9 & 1 & 99 & 0.0 & 8.7 \\
\hline North America & 263 & 0.4 & 1 & 19 & 0.1 & 0.8 \\
\hline Oceania & 26 & 0.04 & 0 & 5 & 0.0 & 0.2 \\
\hline Other & 72 & 0.11 & 0 & 5 & 0.0 & 0.4 \\
\hline \multicolumn{7}{|l|}{ Educational level } \\
\hline Compulsory ( $\leqslant 8$ years) & 4326 & 6.3 & 28 & 300 & 1.9 & 13.7 \\
\hline Compulsory (9-10 years) & 6206 & 9.1 & 75 & 276 & 4.8 & 13.5 \\
\hline Upper secondary (<3 years) & 14,899 & 21.8 & 146 & 782 & 10.0 & 32.3 \\
\hline Upper secondary (3-4 years) & 12,610 & 18.5 & 178 & 508 & 14.9 & 23.7 \\
\hline University or university college ( $<3$ years) & 11,027 & 16.1 & 143 & 534 & 11.5 & 19.7 \\
\hline University or university college ( $\geqslant 3$ years) & 17,799 & 26.1 & 188 & 1067 & 13.0 & 45.0 \\
\hline Licentiate or $\mathrm{PhD}$ & 1032 & 1.5 & 5 & 88 & 0.3 & 5.4 \\
\hline Missing & 404 & 0.6 & 2 & 27 & 0.1 & 2.4 \\
\hline \multicolumn{7}{|l|}{ Occupational class } \\
\hline Unskilled manual & 8618 & 12.6 & 59 & 442 & 3.9 & 23.9 \\
\hline Skilled manual & 7150 & 10.5 & 33 & 440 & 2.3 & 18.2 \\
\hline Lower non-manual & 9949 & 14.6 & 133 & 384 & 10.7 & 19.3 \\
\hline Intermediate non-manual & 17,300 & 25.3 & 191 & 793 & 16.7 & 29.0 \\
\hline Higher non-manual & 13,491 & 19.8 & 119 & 777 & 9.4 & 36.9 \\
\hline Self-employed & 5421 & 7.9 & 58 & 266 & 5.1 & 14.3 \\
\hline Missing & 6374 & 9.3 & 112 & 248 & 7.1 & 16.1 \\
\hline \multicolumn{7}{|l|}{ Type of housing } \\
\hline Condominium & 15,674 & 23.0 & 57 & 1113 & 3.4 & 55.5 \\
\hline Tenant-owned & 20,885 & 30.6 & 63 & 1483 & 4.4 & 67.3 \\
\hline Own house or terraced house & 29,983 & 43.9 & 41 & 1741 & 2.6 & 79.0 \\
\hline Housing for elderly & 283 & 0.4 & 2 & 22 & 0.1 & 1.3 \\
\hline Lodger/student housing & 442 & 0.7 & 5 & 30 & 0.2 & 2.0 \\
\hline Sublet housing & 496 & 0.7 & 2 & 28 & 0.1 & 1.5 \\
\hline Other & 540 & 0.8 & 3 & 49 & 0.2 & 2.2 \\
\hline \multicolumn{7}{|l|}{ Income fifths (mean yearly income ${ }^{a}$ ) } \\
\hline $1(890)$ & 13,656 & 20.0 & 177 & 611 & 15 & 34 \\
\hline $2(1395)$ & 13,666 & 20.0 & 175 & 568 & 12 & 23 \\
\hline $3(1876)$ & 13,660 & 20.0 & 197 & 513 & 17 & 23 \\
\hline $4(2506)$ & 13,661 & 20.0 & 186 & 670 & 16 & 24 \\
\hline $5(4864)$ & 13,660 & 20.0 & 106 & 732 & 10 & 39 \\
\hline
\end{tabular}

No. of residential areas: 39; mean observations/area: 1751.4; minimum size: 1113; maximum size: 2735 .

aHundreds of Swedish kronor. 


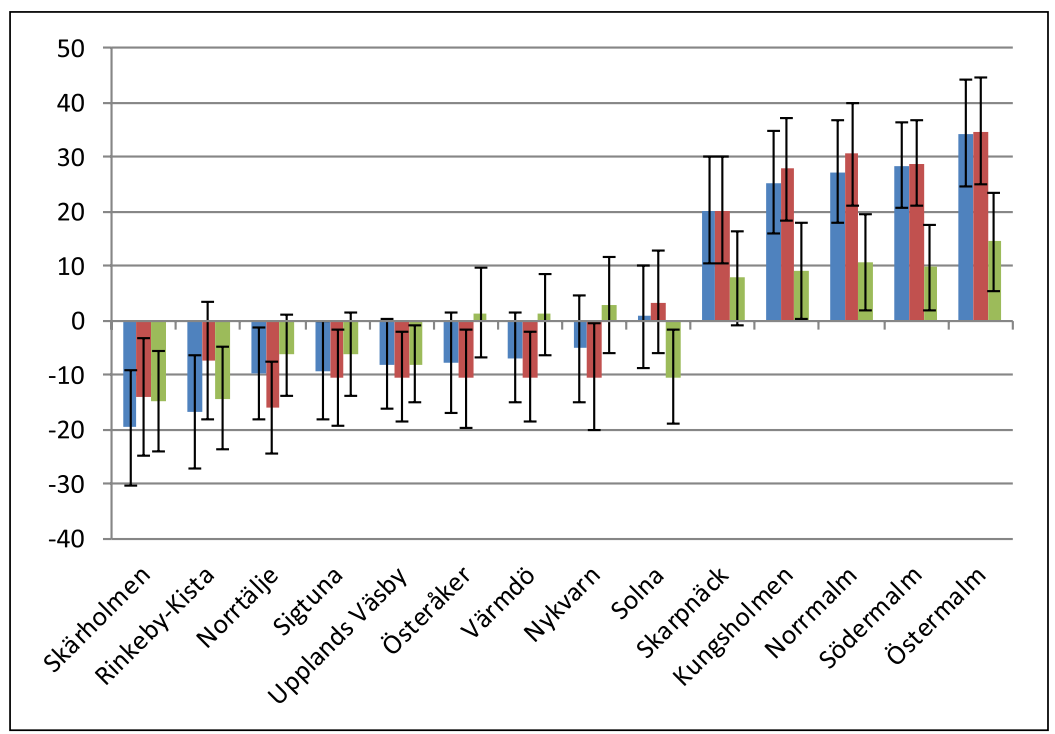

Figure 1. Areas in Stockholm County where the mean time (min/week) spent on bicycling and walking differs statistically significantly from the county mean in at least one model: empty (blue), adjusted for individual level sociodemographic factors (red) and adjusted for individual sociodemographic factors as well as housing at the individual and area level (green).

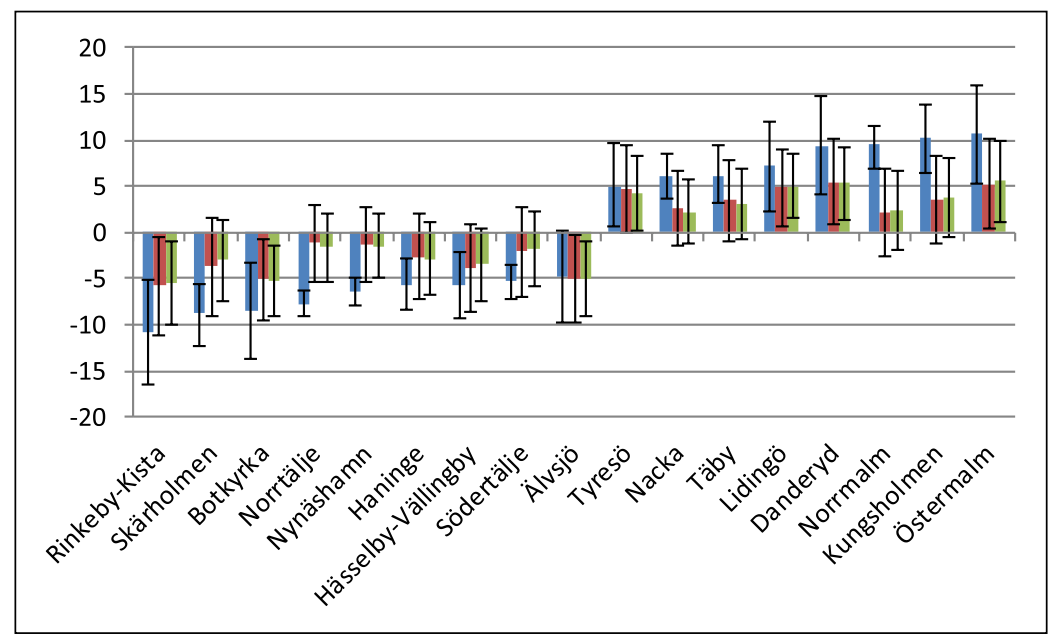

Figure 2. Areas in Stockholm County where the mean time ( $\mathrm{min} / \mathrm{week}$ ) spent on physical exercise differs statistically significantly from the county mean in at least one model: empty (blue), adjusted for individual level sociodemographic factors (red) and adjusted for individual sociodemographic factors as well as housing at the individual and area level (green).

$\min /$ week, corresponding to a decrease of $45 \%$. Adjusting for housing had no additional effect on the results.

\section{Home- and household work and gardening}

On average, residents in Stockholm County spent 10 h $45 \mathrm{~min} /$ week doing home- and household work and gardening (SD $7 \mathrm{~h} 26 \mathrm{~min} /$ week). The difference between the areas where people spent the most and the least time doing home- and household work was 3 h $54 \mathrm{~min} /$ week (areas Norrtälje and Norrmalm; Figure 3). Adjusting for sociodemographic factors at the individual level reduced the geographical differences between the areas to $2 \mathrm{~h} 39 \mathrm{~min}$ (corresponding to a decrease of $32 \%$ ). Further adjustment for housing reduced the maximum between-area difference to $1 \mathrm{~h}$.

\section{Sedentary activities (sitting/watching TV/reading)}

On average, residents of Stockholm County spent $15 \mathrm{~h} 31 \mathrm{~min} /$ week (SD 8 h $35 \mathrm{~min} /$ week) sitting/ watching TV/reading, i.e. being physically inactive. The difference between the two most dissimilar districts was $3 \mathrm{~h} 46 \mathrm{~min} /$ week (areas Danderyd and 


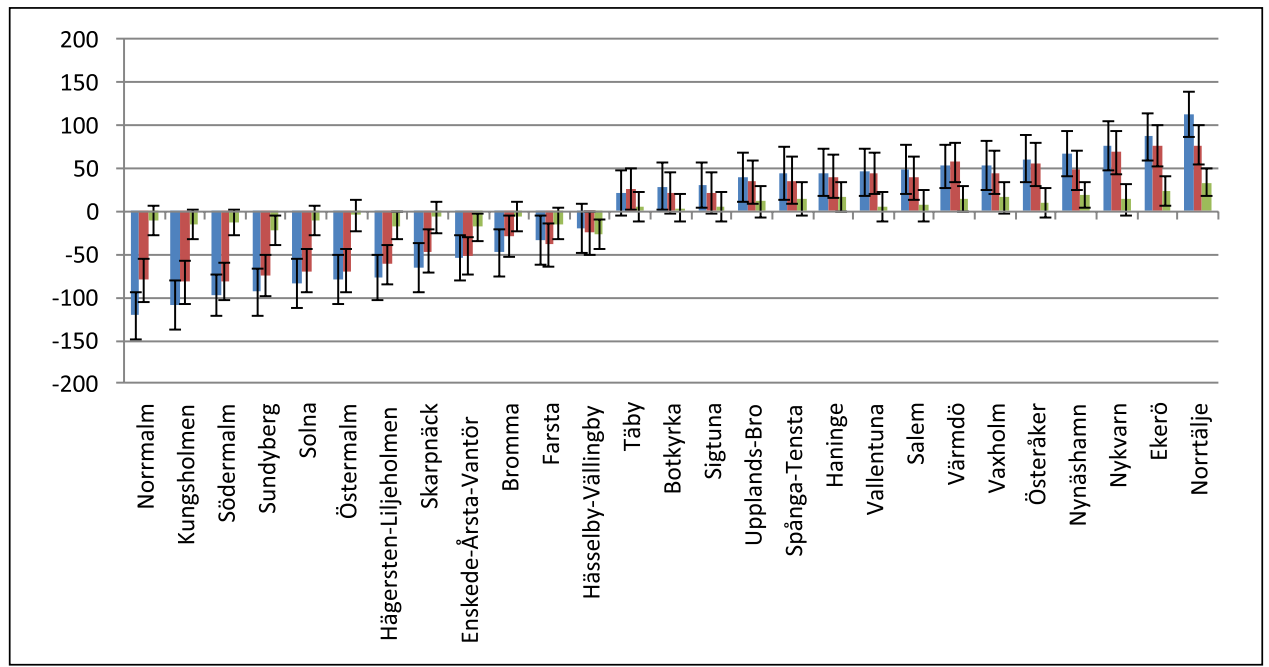

Figure 3. Areas in Stockholm County where the mean time ( $\mathrm{min} /$ week) spent on home and household work and gardening differs statistically significantly from the county mean in at least one model: empty (blue), adjusted for individual level sociodemographic factors (red) and adjusted for individual sociodemographic factors as well as housing at the individual level (green).

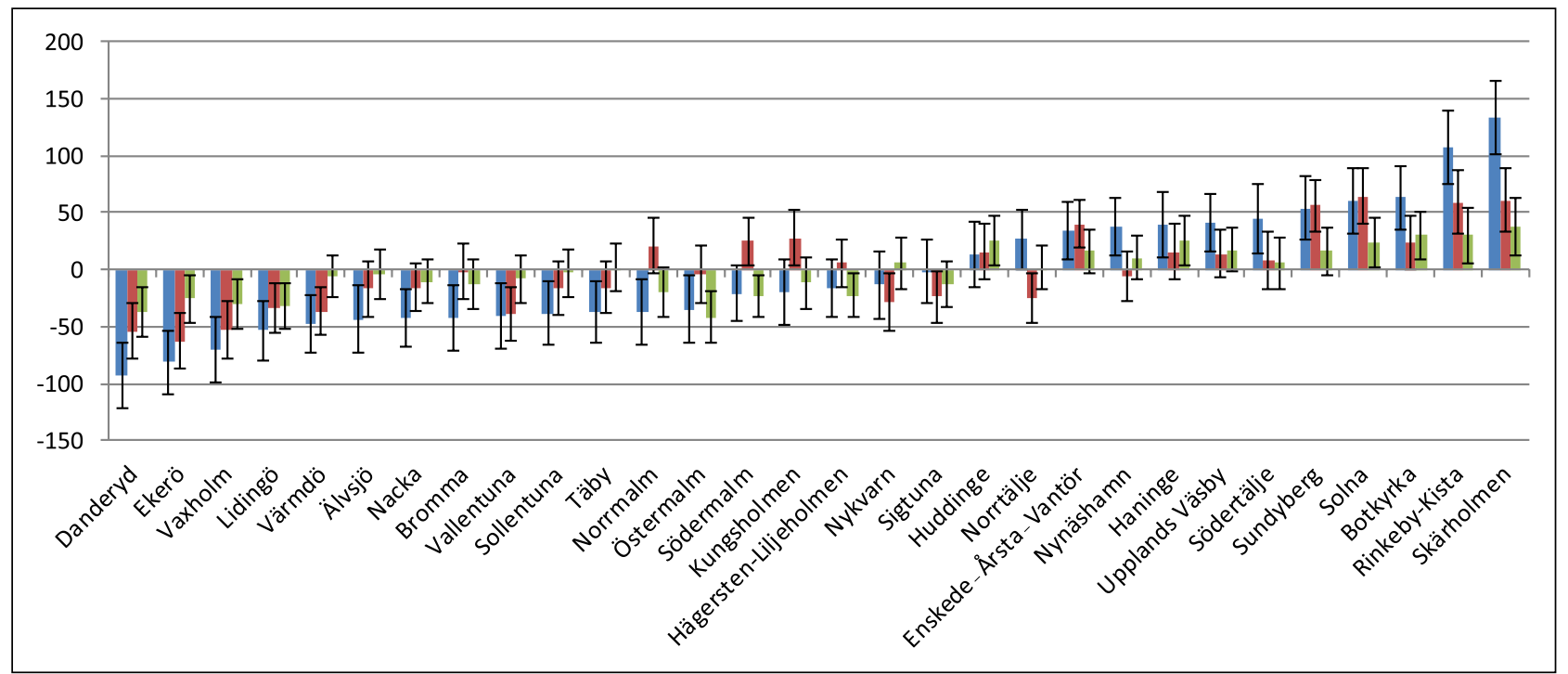

Figure 4. Areas in Stockholm County where the mean sedentary leisure time (min/week) differs statistically significantly from the county mean in at least one model: empty (blue), adjusted for individual level sociodemographic factors (red) and adjusted for individual sociodemographic factors as well as housing at the individual level (green).

Skärholmen; Figure 4). After adjusting for sociodemographic differences at the individual level, the maximum estimated area difference decreased to just above $2 \mathrm{~h} /$ week (corresponding to a decrease of $44 \%$ ). Adjustment for housing reduced the maximum between-area difference even further to $1 \mathrm{~h}$ $20 \mathrm{~min} /$ week.

\section{Discussion}

We found that there are differences in leisure time physical activity levels between areas in Stockholm County that cannot be explained by individual sociodemographic characteristics alone. The results varied depending on which domain of physical activity was analysed; the largest differences in effect sizes were observed for walking and cycling.

One possible explanation for the regional differences in walking and bicycling is the physical planning of different geographical areas. In our data, the difference in walking and bicycling between the most and the least active areas was reduced by $40 \%$ after adjustment for an indicator of the physical environment (area density, measured as the proportion of residents living in their own house or in a terraced house). With more detailed measures of area 
characteristics (e.g. bicycle lanes and separation of car and pedestrian/bicycle traffic), it is possible that even more of the area differences could be explained.

Only minor regional differences in exercise were found between different parts of Stockholm County. The weekly difference between the area with the highest and the lowest activity level was $20 \mathrm{~min}$ or $0.22 \mathrm{SD}$. These regional differences could largely be explained by differences in population composition. After adjustments for sociodemographic characteristics, the difference between the areas almost halved. The small remaining difference was not sensitive to area density.

An unexpected finding was the large effect of individual housing on area differences in household work and physical inactivity. Much of the regional difference in these two domains of physical activity was explained by the type of housing: people living in apartments spend less time doing household work and more time in sedentary activities than people living in their own houses. According to Swedish time use surveys, television-watching is the largest contributor to leisure time sedentary activities [22].

One of the strengths of this study is the large population-based sample, including several measures of socioeconomic position. As in all surveys, it is possible that non-response may have biased our results. The response rate was associated with socioeconomic position, which, in turn, is known to influence lifestyle, meaning that those answering the questionnaire might lead healthier lives than those who did not answer. Thus the analytical sample was probably less representative of the underlying population in the less affluent areas. Taken together, this would result in an overestimation of the average physical activity in the county, but an underestimation of the regional differences. Because our analyses were based on cross-sectional data, we cannot assess the causal effect of geographical area on physical activity. It is possible that the observed differences are due to selfselection, e.g. that the will or ability to be physically active affects what area you choose to live in. It is worth emphasizing that our study compared the physical activity in different districts and municipalities with the average physical activity in the county. This means that the results do not tell us whether residents are sufficiently physically active. It is also possible that people compensate for a lack of physical activity within one of the domains with increased physical activity in another: the person who cycles to work may exercise less and vice versa.

Regional differences in physical activity in Stockholm County have been recognized previously $[9,10]$. Our study confirms that there are statistically significant differences in physical activity and shows that the differences decrease, but do not disappear completely, after adjusting for individual sociodemographic characteristics. Thus there are probably other factors that affect the degree of physical activity in the population. There are at least three possible explanations for the remaining area differences: (a) remaining individual differences, i.e. differences in population composition that we were not able to adjust for (e.g. remaining sociodemographic differences); (b) differences in the social context (e.g. social norms and/or policies that support or discourage physical activity, social capital); and (c) differences in the physical environment [23]. Most likely, all three explanations act together.

This study contributes to the ongoing debate regarding to what degree physical activity can be influenced through planning of the physical environment and/or local policies [24,25]. It lends further support to the claim that cycling and walking are two possible targets for area level interventions [26-30]. Whereas a recent study found clear associations between different environmental characteristics of the residential area and moderate to vigorous intensity physical activity [31], our study suggests that it may be physical activity in the low to moderate end of the scale (sedentary activities, household work, walking and bicycling) rather than vigorous activity (exercise) that is most sensitive to residential area differences (including differences in type of housing).

Our study highlights the possible importance of contextual factors for walking and bicycling and is in line with the interpretation that a high residential density leads to more physical activity of this kind. However, high density comes with a large proportion of inhabitants living in apartments and living in an apartment was, in turn, linked to less physical activity in the form of housework as well as more inactivity in front of the television. If these findings are correct, then walkingand bicycle-friendly areas may also be 'televisionfriendly' and researchers and policy-makers should be aware of this possible trade-off. That differences in exercise seem to be mainly driven by individual socioeconomic status weakens the case for policy-makers hoping to be able to plan their way to more intensively active citizens through changes in the environment.

\section{Acknowledgements}

This work was partly based on an extensive Swedish report prepared for Stockholm County Council [32].

\section{Declaration of Conflicting Interests}

The author(s) declared no potential conflicts of interest with respect to the research, authorship, and/or publication of this article. 


\section{Funding}

The author(s) received no financial support for the research, authorship, and/or publication of this article.

\section{References}

[1] Li J and Siegrist J. Physical activity and risk of cardiovascular disease - a meta-analysis of prospective cohort studies. Int $\mathcal{F}$ Environ Res Public Health 2012;9:391-407.

[2] Brown JC, Winters-Stone K, Lee A, et al. Cancer, physical activity, and exercise. Compr Physiol 2012;2:2775-809.

[3] Helmrich SP, Ragland DR, Leung RW, et al. Physical activity and reduced occurrence of non-insulin-dependent diabetes mellitus. N Engl f Med 1991;325:147-52.

[4] World Health Organization. Global recommendations on physical activity for health. Geneva: World Health Organization, 2010.

[5] Conn VS, Hafdahl AR and Mehr DR. Interventions to increase physical activity among healthy adults: meta-analysis of outcomes. Am F Public Health 2011;101:751-8.

[6] Foster C, Richards J, Thorogood M, et al. Remote and web 2.0 interventions for promoting physical activity. Cochrane Database Syst Rev 2013;9:CD010395.

[7] Richards J, Hillsdon M, Thorogood M, et al. Face-to-face interventions for promoting physical activity. Cochrane Database Syst Rev 2013;9:CD010392.

[8] Roux L, Pratt M, Tengs TO, et al. Cost effectiveness of community-based physical activity interventions. Am F Prev Med 2008;35:578-88.

[9] Burström B, Burström K and Corman D. Livsvillkor, levnadsvanor och hälsa $i$ Stockholms län [Living conditions, health behaviours and health in Stockholm County]. Report 2014:3. Stockholm: Centre for Epidemiology and Community Medicine, Stockholm County Council, 2014 [in Swedish].

[10] Backhans M, Stjernschantz Forsberg J and Lager A (eds). Folkhälsorapport 2015 [Public health report 2015]. Stockholm: Centre for Epidemiology and Community Medicine, Stockholm County Council, http://folkhalsoguiden.se/ amnesomraden/folkhalsoarbete/statistik/folkhalsa-pa-karta/ (2015, accessed 20 October 2016) [in Swedish].

[11] Rasmussen F, Bjermo H, Kark M, et al. Geografiska variationer $i$ övervikt och fetma $i$ relation till matvanor och fysisk aktivitet $i$ Stockholms län [Geographical variation in overweight and obesity in relation to diet and physical activity in Stockholm County]. Report 2014:7. Stockholm: Centre for Epidemiology and Community Medicine, Stockholm County Council, 2014 [in Swedish].

[12] Beenackers MA, Kamphuis CB, Giskes K, et al. Socioeconomic inequalities in occupational, leisure-time, and transport related physical activity among European adults: a systematic review. Int f Behav Nutr Phys Activ 2012;9:116.

[13] Svensson AC, Fredlund P, Laflamme L, et al. Cohort profile: The Stockholm Public Health Cohort. Int $\mathcal{f}$ Epidemiol 2013;42:1263-72.

[14] Statistics Sweden. Socioekonomisk indelning: SEI [Swedish socioeconomic classification]. Stockholm: Statistics Sweden, 1983 [in Swedish].
[15] Statistics Sweden. Integrated database for labour market research. Report 2011:4. Stockholm: Statistics Sweden, 2011.

[16] Norman A, Bellocco R, Bergstrom A, et al. Validity and reproducibility of self-reported total physical activity-differences by relative weight. Int $\mathcal{F}$ Obes Relat Metab Disord 2001;25:682-8.

[17] Orsini N, Bellocco R, Bottai $M$, et al. Validity of selfreported total physical activity questionnaire among older women. Eur $\mathcal{F}$ Epidemiol 2008;23:661-7.

[18] Orsini N, Bellocco R, Bottai M, et al. Reproducibility of the past year and historical self-administered total physical activity questionnaire among older women. Eur f Epidemiol 2007;22:363-8.

[19] Rahman I, Bellavia A, Wolk A, et al. Physical activity and heart failure risk in a prospective study of men. fACC Heart Fail 2015;3:681-7.

[20] Frank LD, Schmid TL, Sallis JF, et al. Linking objectively measured physical activity with objectively measured urban form: findings from SMARTRAQ. Am 7 Prev Med 2005;28:117-25.

[21] Saelens BE, Sallis JF and Frank LD. Environmental correlates of walking and cycling: findings from the transportation, urban design, and planning literatures. Ann Behav Med 2003;25:80-91.

[22] Statistics Sweden En undersökning om svenska folkets tidsanvändning 2010/11 [Swedish time use survey 201/11]. Report 123. Stockholm: Statistics Sweden, 2012 [in Swedish].

[23] McNeill LH, Kreuter MW and Subramanian SV. Social environment and physical activity: a review of concepts and evidence. Soc Sci Med 2006;63:1011-22.

[24] Baker PR, Francis DP, Soares J, et al. Community wide interventions for increasing physical activity. Cochrane Database Syst Rev 2015;1:CD008366.

[25] Bonell C, Wells H, Harden A, et al. The effects on student health of interventions modifying the school environment: systematic review. $\mathcal{F}$ Epidemiol Community Health 2013;67:677-81.

[26] Goodman A, Panter J, Sharp SJ, et al. Effectiveness and equity impacts of town-wide cycling initiatives in England: a longitudinal, controlled natural experimental study. Soc Sci Med 2013;97:228-37.

[27] McCormack GR and Shiell A. In search of causality: a systematic review of the relationship between the built environment and physical activity among adults. Int $\mathcal{F}$ Behav Nutr Phys Activ 2011;8:125.

[28] Ogilvie D, Egan M, Hamilton V, et al. Promoting walking and cycling as an alternative to using cars: systematic review. BMF 2004;329:763.

[29] Ogilvie D, Foster CE, Rothnie H, et al. Interventions to promote walking: systematic review. BM7 2007;334:1204.

[30] Yang L, Sahlqvist S, McMinn A, et al. Interventions to promote cycling: systematic review. BMF 2010;341:c5293.

[31] Sallis JF, Cerin E, Conway TL, et al. Physical activity in relation to urban environments in 14 cities worldwide: a crosssectional study. Lancet 2016;387:2207-17.

[32] Stjernschantz Forsberg J, Seblova D, et al. Områdesskillnader $i$ fysisk aktivitet [Area differences in physical activity]. Scientific report 2015:2. Stockholm: Centre for Epidemiology and Community Medicine, Stockholm County Council, 2015 [in Swedish]. 